SHS Web of Conferences 10, 00026 (2014)

DOI: $10.1051 /$ shsconf $/ 20141000026$

C Owned by the authors, published by EDP Sciences, 2014

\title{
Quality of life of families with children with disability in the area of physical wellbeing in Latvia
}

\author{
J. Millere ${ }^{1}$ and S. Senkane ${ }^{2}$ \\ ${ }^{1}$ Latvia University of Agriculture, Latvia \\ ${ }^{2}$ Latvia University, Latvia
}

\begin{abstract}
Family quality of life, just like quality of life in general is multidimensional by nature and reflects interaction of different areas and their influence on family life; for this reason it becomes possible to study it in the context of different approaches. Analyzing the areas of family quality of life highlighted by different authors it can be concluded that the analysis of family quality of life must include the following areas: material, physical, social and emotional wellbeing, and also describe the factors that affect family wellbeing. The research of family quality of life is crucial in order to reflect on family's ability to meet their needs, while the possibility for families to meet the needs largely depends on the support provided by the state, municipalities, NGOs and the society as a whole. Based on the study results, it is possible to identify the type of support needed for meeting children's special needs, and also to highlight the tendencies in how the lack of this support in area of physical wellbeing affects their family quality of life. This study reflects the factors that affect the quality of life in the area of physical wellbeing of the families with disabled children.
\end{abstract}

\section{Introduction}

The quality of life of the families with the children with disability is often affected by conditions that are connected to the meeting of these needs which in turn restricts ability of these families to meet their needs. Parents of these children quite often are limited in their employment, as well as education opportunities that interdicts the necessary resources for these families to meet their needs, as well as get involved in cultural life of the community, create social contacts, and ensure life condition adequate to the family needs. Such a situation has developed not just because of the socio-economic situation in the country, but also due to the disinterested disposition of the society towards the phenomenon of special needs and the limited capacity of the state to provide the necessary support. In January $1^{\text {st }}, 2010$, 7009 families were registered in Latvia as the ones that receive state support for a child with disability, which tells us that there are children with disability in these families that have been granted disability. (Supplement to the family state benefit, 2010) Families with children with disability make up $2.7 \%$ of all families with underage children. (Number of recievers ..., 2010).

Aim of the research is to show the quality of life of the families with children with disability and its influencing factors in the area of physical wellbeing.

This is an Open Access article distributed under the terms of the Creative Commons Attribution License 4.0, which permits unrestricted use, distribution, and reproduction in any medium, provided the original work is properly cited. 


\section{Materials and methods}

From January, 2010 till April, 2011 the author conducted a quantitative research in order to study the quality of life of families with children with disability and the factors affecting it, accentuating the role of social policy in the provision of life quality. The volume of the sample was formed according to $6 \%$ sample error that is acceptable in the studied that do not put a claim on the comparison of statistically significant data (Ядов, 2007:98). The sample of the study is a random stratified proportional sample; the statistical regional division was used as a basis of the grouping of strata. The sample strata were formed in accordance with regional division and proportionally to the main group. Research method used in the study is structured interviews. In the survey participated 272 families: 247 mothers, 11 grandmothers, 15 fathers a one other person - child's' aunt. The data obtained through the survey was processed using SPSS program, but the graphic data coverage was done using Excel data processing program. SPSS program carried out the calculations in connection with data processing. Using the Chi-square test, the author estimated the proportionally statistical significance between variables. This survey describes children's special needs and the suitable care by dividing families into three groups: families with children that need full care, families with children that need a sitting and families with children that may or may not need any help.

In the survey, area of physical wellbeing includes: housing, education, health care, municipality/state support in an area of physical wellbeing, providing with technical facilities, availability of the transport, free time and relaxation.

\section{Theoretical explanation of quality of life}

The quality of life describes the level of satisfaction of human needs that is determined in accordance with the existing norms, habits and traditions of particular society, as well as in comparison with the level of personal ambition. The definition of the quality of life depends on the content included into the study of the quality of life. For example, the researchers of the quality of life in England have split all quality of life definition into four types:

The first type accentuates objective indicators and explains quality of life through the living conditions that also implies individual life satisfaction.

The second type - just like the first one - highlights objective indicators of the quality of life, but the difference is that these definitions views quality of life as satisfaction with living conditions. This type of definitions allows dividing the areas of living conditions and assessing the quality of life based on the subjective satisfaction of an individual with them.

The third type includes both living conditions and individual's satisfaction with them in the concept of quality of life. This type of definition has both the objective and subjective dimensions of quality of life.

The fourth type explains the quality of life by the objective and subjective dimension and their significance is assessed through a special scale. This type of definition gives a comprehensive perspective of individual's quality of life considering his or her values. (Quality of Life and ..., 2006)

The choice of quality of life definitions depends not only on what scientific framework is used for particular quality of life survey, but also on the specifics of the target group and the goal of the survey. If the research is focused on the family quality of life, an author must use the definition that point both to the assessment of family living conditions and allow assessing the quality of life of families considering their own subjective satisfaction with their living conditions. Thus it can be concluded that the quality of life is characterized by the individual's satisfaction with the current living conditions that provide satisfactions of the needs in all areas that affect his or her everyday life.

The concept of quality of life is complex by nature and can be viewed from the theoretical viewpoint of various fields of science; also it can be ascribed different contents. Referring to previously discussed 


\section{Int. Conf. SOCIETY. HEALTH. WELFARE.}

theoretical postulates that are connected to the specifics of the explanation of quality of life , the conclusion can be that the concept of quality of life reflects both the opportunities that are given to the members of the society and the factors that influence the use of this opportunities and the aspect that affect the everyday life, for example, living conditions, relationships between family members, recreational opportunities, cultural involvement, as well as an assessment of the everyday life in accordance with one's opinion about good everyday life. It indicates that an explanation of the quality of life is underpinned by particular scientific postulates that are focused on the theoretical explanation of the content of the concept of quality of life. Also it is possible to analyze it using different indicators and on different levels: micro, mezo and macro levels, that is on individual, group and societal level (Stepčenko, 2006). Joseph Sirgy (2001) believes that quality of life can be studied on four levels individual level, family level, and community/regional and society level. For example, Anthony Giddens has most vividly revealed the essence of the integration of micro and macro levels and its role in the analysis of social processes. According to Giddens' theory of structuration, the quality of life is a type of social reality that is made up of particular social practices; those practises are made up of social subjects (structures and agents) and they come into effect within different systems. According to Giddens, any cyclical social relationships form a social system. (Giddens, 1984, 1-28). In order to ensure the quality of life necessary to meet family needs, family members must get involved in a large number of social practises involving the provision of material, emotional, social and physical wellbeing.

According to Bourdieu, the social practises of individuals are made of habitus, the resources available to individuals and the field that determines the rules of actions. (Bourdieu et al., 1996, 98). From the basic insights of Bourdieu's theory, it can be concluded that the quality of life is made of a body of social practices that ensure individual's wellbeing. Social practices are made of the cultural, symbolic, economic and social capital, as well as the field and the conditions of the field where individuals or social groups operate. Quality of life is influences by such factors as individual's ability to manage the available resources, as well as environment that not just affect individual's ability to obtain the necessary resources, but also largely determine individual's possibilities to improve quality of life.

Family quality of life, just like quality of life in general is multidimensional by nature and reflects interaction of different areas and their influence of family life; for this reason it becomes possible to study it in the context of different approaches. Analyzing the areas of family quality of life highlighted by different authors and organizations it can be concluded that the analysis of family quality of life must include the following areas that characterize family quality of life: material, physical, social and emotional wellbeing, and also describe the factors that affect family wellbeing.

\section{Results}

Physical wellbeing is mostly associated with environment where the family quality of life is formed and that affects other areas of quality of life; environment is reflected by the conditions that form it. As a result of factor analysis, the author singled out two factors that reflect the conditions necessary for the satisfaction of family needs : conditions adequate to meet basic needs; that includes home and community environment characterized by the conditions that are necessary for the families to meet basic needs; they include a safe, warm and light lodging, as well as healthy nutrition and safe surroundings; and conditions necessary for recreation and self-realization points out to the conditions that ensure the environment that is good not just adequate for basic needs, but also for recreation and self-realization: that would be sufficiently large housing that provides opportunities for all family members to rest and time for self-realization.

Physical wellbeing of the families is largely affected by material provision. Material provision influences not just the chances of the families to obtain the resources necessary for meeting their needs, but also largely influence the conditions necessary for meeting the family needs. The calculations show that material provision affects the chances of the families to upgrade their housing: the higher the 


\section{SHS Web of Conferences}

material provision, the bigger the chances to upgrade the housing. Material provision designed to meet the basic needs of the families is not sufficient for the families to upgrade their housing. Material provision mostly affects the chances of the families to live in housing with all amenities; - the calculations provide grounds for this conclusion. The study shows that material provision mostly affect the chances of the families to remodel the housing and install in it all necessary amenities, for example, in-house toiled, bathroom, laundry machine or exchange a housing in critical condition for a better one.

Material provision affects availability of the doctors in the areas of specialists and the distance. When assessing the affect of material provision on physical wellbeing of the families, the conclusion is that not all difficulties in connection with provision of quality of life can be solved through material provision; yet material provision increases the chances to form conditions adequate for meeting the family needs.

Physical wellbeing is affected by social contacts of the families, since the families with disabled children need the support of friends and relatives more than they need material provision. For example, the availability of technical aids is largely affected by social contacts. The study calculations show that the families whose social contacts are not just community or kinship based, but also have the formal component have bigger chances of obtaining the necessary technical aids; it indicates that formal social contacts are necessary for meeting of the special needs of disabled children.

It appears from the analysis of the factors affecting family quality of life that family quality of life is a multidimensional phenomenon that is affected by both structural conditions formed by the society and the involvement of these families in improving of their quality of life, based on the experience of quality of life gained through the socialization process. For example, the families whose experience of quality of life is associated with difficulties quite often get used to these difficulties and do not desire to change their different living conditions. Conclusions made as a result of the study of family quality of life are substantiated by the subjective assessment of family quality of life The study results show that more than a half of the interviewed families form all the regions of Latvia consider their quality of life to be either satisfactory or good. For example, almost a third of the interviewed families from Kurzeme region reside in lodgings without basic amenities; yet $86 \%$ of these families consider their quality of life to be good and satisfactory.

Physical wellbeing is a prerequisite of the provision of quality of life for children with disability, since physical wellbeing includes such areas as suitability of housing and environment to the family needs, also mobility and accessibility of health care. As the study shows, majority of the families live in residences with dwelling space of less than $15 \mathrm{~m}^{2}$ on a family member According to the statistical data, in 2009 average floor space on 1 person was $27.2 \mathrm{~m}^{2}$ (LR Centrālā..., 2010). It signifies that families with disabled children live in dwellings that are smaller than average. As the study shows, most of the interviewed families live in two-room lodgings; even larger number of families live in a single-room lodgings, for example, in Riga city and Riga region; it indicates that these families do not have real opportunity to have rest and that children with disability do not have their own room.

The family quality of life is affected by amenities in the housing, especially if there is a need to satisfy special needs of children that need full care. The study indicates that largest number of families with housing with all amenities reside in Riga and Riga region. A little than third of families in Kurzeme region occupy housing without any amenities; it means that their lodging does not fit the special needs of disabled children. The families there are not able to take a shower or a bath; there is no hot water and central heating in the lodging, also the toilets often are located outside. Proportionally large number of the interviewed families has such lodgings in Latgale region and Zemgale region. As the study data show, families than live in urban areas have dwelling with amenities more often than the ones living in rural areas. Only $8 \%$ of the interviewed families that live in towns have dwelling with no amenities, for example, the source of water and the toilets are outside; there is no hot water inside and no chance to have a wash. In comparison, $30 \%$ of the interviewed families from rural areas face the same problem. There are quite many families in all regions of Latvia that occupy housing with partial amenities: these 


\section{Int. Conf. SOCIETY. HEALTH. WELFARE.}

places are without central heating and sometimes no hot water, - almost half of the families from rural areas and $21 \%$ of the families from towns same the problem.

Housing amenities have a lot to do with the opportunity to satisfy the special needs of disabled children, but housing amenities alone do not create adequate environment to satisfy the special needs of children that need full care. These children need the lodging to be adapted to the specifics of their needs that requires reconstruction of housing and special equipping to provide a way for the children to move around in wheelchairs, take showers or baths, have a room for exercise units and a special type of bed. As the study shows, the majority (72\%) of the interviewed families with disabled children that need special adaptation of housing to their special needs do not occupy that type of housing. Situation is the worst in Latgale region; $82 \%$ of the families with disabled children do not occupy housing adapted for their special needs.

The study results show that majority of the interviewed families are generally satisfied with their lodging and consider it to be satisfactory or good; yet $25 \%$ of the families residing in Latgale region, Zemgale region and Kurzeme region believe their housing to be inadequate. Usually they substantiate this opinion by the lack of amenities, as well as bad condition of the dwelling. The highest assessment to their dwelling was given by the families from Riga city and Riga region.

As a result of the health care reform, the families from the most remote areas experience difficulties in the area of accessibility of health care services, especially if a family does not own a personal vehicle. The study shows that the families from all regions face various difficulties in the area of health care, for example, financial difficulties, inaccessibility of specialists and experts, remote location of health service providers, as well as low quality of health care and indifferent attitude from doctors. It is especially Latgale region and Kurzeme region where the families experience the inaccessibility of necessary specialists; also health care service providers are located a long way from their residence. Low quality of health care services is an issue that the families from Riga and Vidzeme region are the most concerned about.

Most families believe the health care to be acceptable; yet it can be concluded that almost $25 \%$ of the families from Latgale region consider the health care available to them to be bad. The calculations of statistical significance of percentage differences indicate that the assessment of health care is affected by the type of care the disabled children need (p-value is 0,00044$)$. Significant differences are observed among the families with children that need full care and the families whose children need little or no assistance.

The families whose children need full care face different problems that could be reduced by an opportunity to have an assistant. As the study shows, families from all regions equally feel the lack of professional assistance. This lack is felt the most by the families in Riga city and Zemgale region; and it is felt the least in Kurzeme region, which indicate that the families from these regions have resigned to the situation and have gotten used to difficulties. One-parent families feel smaller need for an assistant than nuclear families. As it is stated by the families, they are used to the difficulties and can manage daily duties; most of the mothers that take care of their children believe no-one can do a better job.

One of the main difficulties the families face in the area of physical wellbeing is the lack of personal vehicle; for these families, many places are totally out of reach. The main problem caused by a lack of a personal vehicle is inability to get to the necessary places, especially at the moments when it is the most important, since there are still areas in Latvia with not public transportation. It significantly aggravates the quality of life of these families. In general $56 \%$ of the interviewed families has access to the adequate transport to get to the necessary places.

The quality of life of the families with disabled children is largely affected by the availability of technical aids. The lack of technical aids for disabled children denies them the opportunity to move; also available technical aids do not always match the special needs of disabled children, for example, orthopaedic braces or wheelchairs are too small or low-grade. The study shows that the greatest lack of technical aids is experienced by the families from Kurzeme region and Latgale region. The smallest 


\section{SHS Web of Conferences}

numbers of families whose children experience the lack of necessary technical aids reside in Riga and Vidzeme region. It can be concluded that the families face this problem in all regions and it tells of the gaps in social policy.

\section{Discussion}

Family quality of life for families with disabled children is affected by the availability of resources necessary to meet their needs. The resources necessary to meet their special needs depend on the type of child's functional disorder and the suitable care. Satisfaction of children's special needs affects family quality of life in all areas regardless of the care type needed; yet it especially affects the quality of life of those families that have the children that need full care or sitting. The support in the area of physical wellbeing does not recompense the influence of special needs of the disabled children on family quality of life, since available support is either suitable to the family needs or these families face different obstacles in receiving the necessary support - the state provides children with disability necessary technical aids; yet $51 \%$ of families do not have access to these aids. Besides, technical means provided by the state sometimes do not match the need; for example, orthosis and/or wheelchair is too small and of bad quality. $71 \%$ of families have not received support for accommodating the dwelling to the special needs of children.

As the survey shows, family quality of life is characterized not by objective life condition, but by subjective satisfaction of families with their living conditions; so often families are used to "bad" living conditions and assess their quality of life as satisfactory or even good. And vice versa; some families enjoy fairly good living conditions, yet they are not satisfied with their quality of life as not matching their needs and desires. It is told by the families that in order to meet their needs and improve their quality of life, they would need qualified assistance, personal transportation, housing with amenities, more financial resources, personally owned, not rented dwelling, as well as positive attitude and consideration from the people.

\section{Conclusions}

- The quality of life is described by individuals' satisfaction with the current life conditions that meet the needs in all the areas affecting their everyday life. Family quality of life reflects the conditions through which family needs are met and family members have opportunity to do what is important to them.

- Quality of life of families with disabled children is affected by emotional tension caused by meeting their special needs; so it would be necessary not only offer social assistance to these families, but also social services, for example, psychological consultations or rehabilitation. Quite often social assistance to these families is given mechanically without going into the causes of the problems.

- The support to the families with disabled children provided by the states social policy recompenses the effect of the special need of disabled children on family quality of life only in the area of material wellbeing. The financial support from the state promotes the economic security of $79 \%$ of the respondents; also $97 \%$ of the families that have been granted low-income status receive financial support from the local government.

- The survey reflects the gap in accessing of information about social assistance opportunities and social services provided by municipalities. The lack of information prevents families to use the material support provided by the municipalities, mostly to poor families; this degrades their quality of life in all areas. It also prevents them from using social services that at times is even more necessary than material support, for example, psychological support in the area of emotional wellbeing. 
Int. Conf. SOCIETY. HEALTH. WELFARE.

- Families' with the children that need full care assessment of medical care is lower than that of the other families; it tells us that in the country families face problems with diagnostics and treatment of specific diseases.

The survey was carried out using the financial support of the European Social Fund project "Support for doctoral study program for learning and research degrees at the Stradins University of Riga".

\section{References}

[1] Bourdieu P., Wacquant L.J.D. (1996). An invitation to Reflexive Sociology. Cambridge, Polity Press, pp. 94-119.

[2] Defining Quality of Life and Well-being. (2006). In: Quality of Life and Well-being: Measuring the Benefits of Culture and Sport: Literature Review and Thinkpiece. [Tiešsaiste] Sk. 12.05.2010. Pieejams: http://www.scotland.gov.uk/publications/2006/01/13110743/2.

[3] Giddens A. (1984). The Constitution of Society: outline of the theory of structuration. Los Angeles, University of California Press, pp. 402. [Tiešsaiste] Sk.18.09.2010. Available: http://books.google.com/books?id=cV8xnSIa0IC\&printsec=frontcover\&hl=lv\&source.

[4] Habermas J. (1999). Moral Consciousness and Communicative Action. Baskerville by DEKR Corporation.

[5] Number of recievers of the States Family benefit. Statistical data on January $1^{\text {st }}$, 2010. Available: http://www.vsaa.lv/en/budget-and statistics/statistics?gid=2\&year=2009\&year=2010\&tid=100-.

[6] Sirgy M. J. (2001). Handbook of Quality-of-Life Research: An Ethical Marketing Perspective. In: Social Indicators Research Series, Netherlands, Kluwer Academic Publishers, Vol. 8, pp. 65-86.

[7] Stepčenko A. (2006). Dzīves kvalitātes indikatori Eiropas Savienībā. Metodoloǵiski jautājumi. In: Latvijas Universitātes raksti. 701.sējums: Sociologija. Rīga, Latvijas Universitāte, 142-154 lpp.

[8] Supplement to the family benefit. Statistical data on January $1^{\text {st }}, 2010$.

[9] Ядов В.А. (2007). Стратегия сочиологического исследования. Москва, Омега-Л, 567 стр. 